\title{
Ultrastructure and molecular phylogeny of four new species of monoxenous trypanosomatids from flies (Diptera: Brachycera) with redefinition of the genus Wallaceina
}

\author{
Vyacheslav Yurchenko ${ }^{1 *}$, Jan Votýpka ${ }^{2,3^{*}}$, Martina Tesařová ${ }^{3}$, Helena Klepetková2 ${ }^{2}$ Natalya Kraeva ${ }^{1}$, \\ Milan Jirkư ${ }^{3}$ and Julius Lukeš ${ }^{3,4}$ \\ ${ }^{1}$ Life Science Research Centre, University of Ostrava, Ostrava, Czech Republic; \\ ${ }^{2}$ Department of Parasitology, Faculty of Science, Charles University, Prague, Czech Republic; \\ ${ }^{3}$ Institute of Parasitology, Biology Centre of the Academy of Sciences of the Czech Republic, České Budějovice, Czech Republic; \\ ${ }^{4}$ Faculty of Science, University of South Bohemia, České Budějovice, Czech Republic \\ * These authors contributed equally to this work
}

\begin{abstract}
Four new species of monoxenous kinetoplastid parasites are described from Brachycera flies, namely Wallaceina raviniae Votýpka et Lukeš, 2014 and Crithidia otongatchiensis Votýpka et Lukeš, 2014 from Ecuador, Leptomonas moramango Votýpka et Lukeš, 2014 from Madagascar, and Crithidia pragensis Votýpka, Klepetková et Lukeš, 2014 from the Czech Republic. The new species are described here based on sequence analysis of their spliced leader (SL) RNA, glycosomal glyceraldehyde 3-phosphate dehydrogenase (gGAPDH) and small subunit (SSU) rRNA genes, as well as their morphology and ultrastructure. High-pressure freezing and Bernhard's EDTA regressive staining, used for the first time for monoxenous (one host) trypanosomatids, revealed the presence of viral particles with cytosolic localization in one and unique mitochondrial localization in another species. In accordance with previous observations, our results emphasize a discrepancy between morphology and molecular taxonomy of the family Trypanosomatidae. All four newly described species are represented by typical morphotypes (mainly choano- and promastigotes) and are virtually indistinguishable from other monoxenous trypanosomatids by morphology. Nevertheless, they all differ in their phylogenetic affinities. Whereas three of them grouped within the recently defined subfamily Leishmaniinae, which includes numerous representatives of the genera Leishmania Ross, 1903, Crithidia Léger, 1902 and Leptomonas Kent, 1880, the fourth species clusters together with the 'collosoma' clade (named after 'Leptomonas' collosoma Wallace, Clark, Dyer et Collins, 1960). Here we demonstrate that the 'collosoma' group represents the elusive genus Wallaceina Podlipaev, Frolov et Kolesnikov, 1999. We redefine this genus in molecular terms based on similarities of the respective molecular markers and propose to use this taxon name for the group of species of the 'collosoma' clade.
\end{abstract}

Keywords: Kinetoplastida, Trypanosomatidae, monoxenous kientoplastids, Leishmaniinae, molecular taxonomy, phylogeny

This article contains supporting information (Fig. S1) online at http://folia.paru.cas.cz/suppl/2014-61-2-97.pdf

Until recently, monoxenous (one host) trypanosomatids (Kinetoplastida) of insects were a neglected group of protists. However, they are attracting increasing interest due to their extreme biological diversity combined with an unparalleled richness of their insect hosts (Podlipaev 2001, Maslov et al. 2013). Traditional morphology-based taxonomy of the family Trypanosomatidae put forward about half a century ago (Wallace 1966) and extensively used until present is not supported by modern molecular data (Teixeira et al. 1997, 2011, Yurchenko et al. 2006a,b, Jirků et al. 2012, Borghesan et al. 2013, Maslov et al. 2013). This is exemplified by the canonical genera
Crithidia Léger, 1902 and Leptomonas Kent, 1880, originally defined by the presence of choanomastigotes and promastigotes, respectively, which are clearly polyphyletic. Moreover, morphology of these parasites seems to differ substantially in the insect host and in the culture, making the available morphological traits practically useless (Podlipaev et al. 2004, Votýpka et al. 2012a,b).

To resolve this conflict, a concept of typing units (TUs), which represent operational proxies of molecular species, was adopted by us and others (Westenberger et al. 2004, Maslov et al. 2010, Votýpka et al. 2012a, Borghesan et al. 2013). Here, TUs are defined in terms of nucleotide

Address for correspondence: V. Yurchenko, Life Science Research Centre, University of Ostrava, 71000 Ostrava, Czech Republic. Phone: +420 597092326; Fax: +420 597092382; E-mail: vyacheslav.yurchenko@osu.cz 
sequence divergence of the appropriate genetic marker (Maslov et al. 2013). Three molecular markers - the small subunit (SSU) rRNA, the glycosomal glyceraldehyde phosphate dehydrogenase (gGAPDH) and the kinetoplastid-specific spliced leader (SL) RNA gene repeat - are routinely used in molecular phylogenetic studies of the family Trypanosomatidae (Merzlyak et al. 2001, Hamilton et al. 2004, Yurchenko et al. 2006a,b, Teixeira et al. 2011, Jirků et al. 2012, Votýpka et al. 2012b). The first two genes are fairly conserved and therefore do not provide sufficient resolution for discrimination of the closely related species and/or subspecies, but they are useful in revealing relationships at the generic and/or higher levels. The third genetic marker, the SL RNA gene, combines conserved and variable features and was proven to provide adequate resolution power to distinguish species or even intra-species populations within the family Trypanosomatidae (Westenberger et al. 2004, Votýpka et al. 2010). Because of the small size and substantial sequence divergence of its variable region, the SL RNA marker cannot be used for inferring long-distance (above species or subgenera) relationships.

Despite the fact that a new species-rich genus Blechomonas Votýpka et Suková, 2013 from fleas (order Siphonaptera) has been recently described (Votýpka et al. 2013 ), over $80 \%$ diversity of the monoxenous trypanosomatids documented so far originates from only two insect orders - Heteroptera and Diptera (Votýpka et al. 2010, 2012a, Maslov et al. 2013, Týč et al. 2013). Furthermore, the balance is substantially shifted towards the heteropteran hosts, leaving dipterans underinvestigated. One of the reasons for this bias could be that most brachyceran flies were considered to be infected only by the omnipresent Herpetomonas muscarum Kent, 1881 - see Brun (1974). However, several recent studies have demonstrated that the diversity of trypanosomatids parasitising flies is much higher, both within the genus Herpetomonas Donovan, 1909 (Zídková et al. 2010, Borghesan et al. 2013, Týč et al. 2013), as well as within the family Trypanosomatidae in general (Svobodová et al. 2007, Teixeira et al. 2011, Týč et al. 2013). The blood-sucking feeding habit of many dipteran hosts makes them potential vectors for transmission of the monoxenous flagellates to vertebrates (Maslov et al. 2013, Týč et al. 2013). A few cases of such opportunistic infections have been recently documented in immunocompromised humans and animals (Morio et al. 2008, Srivastava et al. 2010, Singh et al. 2013). More extensive study on biodiversity of the dipteran parasites revealed that they can be found in association with different clades of monoxenous trypanosomatids and that there are no strictly defined boundaries between species parasitising the insect orders Heteroptera and Diptera (Týč et al. 2013).

Over the past few years, clearly polyphyletic status of several genera of the family Trypanosomatidae has been clarified considerably. Currently, all three dixenous genera, Trypanosoma Gruby, 1843, Leishmania Ross, 1903, and Phytomonas Bergey, Harrison, Breed, Hammer et Huntoon, 1923, are recognised as monophyletic (Maslov et al. 1996, 2001, Hamilton et al. 2004), as well as four monoxenous genera, Herpetomonas, Sergeia Svobodová, Zídková, Čepička, Oborník, Lukeš et Votýpka, 2007, Angomonas Souza et Corte-Real, 1991 and Strigomonas Lwoff et Lwoff, 1931 - see Svobodová et al. (2007), Teixeira et al. (2011), Borghesan et al. (2013). In a broad sense, the genus Blastocrithidia Laird, 1959 could also be considered monophyletic (Maslov et al. 2001, Podlipaev et al. 2004, Maslov et al. 2010).

The main confusion rests within the subfamily Leishmaniinae, which is composed of the above-mentioned polyphyletic genera Crithidia and Leptomonas, as well as several representatives of the genus Wallaceina Podlipaev, Frolov et Kolesnikov, 1999 (Merzlyak et al. 2001, Podlipaev et al. 2004, Votýpka et al. 2010, 2012a, Jirků et al. 2012, Týč et al. 2013). Recent studies also demonstrated emergence of several new taxonomic clades that may represent new genera or even subfamilies of the family Trypanosomatidae (Flegontov et al. 2013, Maslov et al. 2013, Votýpka et al. 2013). Our results presented here clarify this rather confusing situation. Along with the description of four new species, we propose to redefine the genus Wallaceina and show that it constitutes a separate monophyletic group of trypanosomatids.

\section{MATERIALS AND METHODS}

\section{Parasite isolation and establishing of cultures}

Insect collection, dissection and microscopic examination of the intestinal content were performed as described previously (Maslov et al. 2007, Yurchenko et al. 2008, 2009, Týč et al. 2013). Primary cultures of parasites were established in the Brain Heart Infusion (BHI) medium supplemented with $10 \mu \mathrm{g} / \mathrm{ml}$ of hemin. To prevent bacterial contamination, the following antibiotics were used: 500 units $/ \mathrm{ml}$ of penicillin, $0.5 \mathrm{mg} / \mathrm{ml}$ of streptomycin or $0.5 \mathrm{mg} / \mathrm{ml}$ of gentamycin. Obtained cultures are deposited in the collections of the Charles University in Prague, Life Science Research Centre of the University of Ostrava, and Institute of Parasitology in České Budějovice, Czech Republic.

\section{Light and electron microscopy}

Light microscopy of Giemsa or 4',6-diamidino-2-phenylindole (DAPI) stained smears was performed as described by Yurchenko et al. (2008). All measurements were taken on Giemsa-stained samples and are expressed in micrometres $(\mu \mathrm{m})$ unless otherwise indicated. For scanning electron microscopy (SEM), cultured cells were fixed in $2.5 \%(\mathrm{v} / \mathrm{v})$ glutaraldehyde in $0.1 \mathrm{M}$ phosphate buffer $(\mathrm{pH} 7.2)$. Then followed transfer to the poly- $L$-lysine-coated coverslips, post-fixation in $2 \% \mathrm{OsO}_{4}$ in $0.1 \mathrm{M}$ phosphate buffer for $2 \mathrm{~h}$, dehydration in an ascending acetone series, critical point-drying with $\mathrm{CO}_{2}$ in Pelco CPD2 (Ted Pella Inc., Redding, CA, USA), and sputtering with gold in a Sputter Coater Polaron chamber (Polaron Ltd., Watford, UK). The cells were observed using a JEOL 7401-F microscope 
(Jeol Europe, Prague, Czech Republic) at accelerating voltage of $80 \mathrm{kV}$.

High-pressure freezing (HPF) is a very rapid method of cryoimmobilization of biological samples by exposing them to liquid nitrogen under a pressure of $2 \times 10^{8} \mathrm{~Pa}$, which prevents the formation of cubic and hexagonal ice crystals that could damage the cells' ultrastructure (Richter 1994). Using HPF, samples up to $200 \mu \mathrm{m}$ thick can be frozen without such ice crystals. Trypanosomatid cells were concentrated by centrifugation and the compact pellet was mixed with a drop of $20 \%$ bovine serum albumin and centrifuged for $1 \mathrm{~min}$ at $3000 \mathrm{rpm}$. Approximately $1 \mu 1$ of cell suspension was directly transferred onto a flat specimen carrier (Leica Microsystems, Vienna, Austria) made of gold-plated copper (height $0.5 \mathrm{~mm}$, inner diameter $1.2 \mathrm{~mm}$, depth $0.2 \mathrm{~mm}$ ) and mounted in a rapid loader for HPF. The specimen carrier was tightly sealed and samples were frozen at a pressure of $2 \times 10^{8} \mathrm{~Pa}$ for $5 \mathrm{~s}$ in a high pressure freezer EM PACT2 (Leica Microsystems). Following freezing, the flat specimen carriers were separated from the loading device pods under liquid nitrogen and transferred into screw-capped containers filled with the frozen substitution medium $\left(2 \% \mathrm{OsO}_{4}\right.$ in $100 \%$ acetone) pre-cooled to $-90^{\circ} \mathrm{C}$. The containers were then placed into a freeze-substitution system Leica AFS (Leica Microsystems) and samples were substituted for $96 \mathrm{~h}$ at $-90^{\circ} \mathrm{C}$, followed by warming to $-20^{\circ} \mathrm{C}$ at $+5^{\circ} \mathrm{C} / \mathrm{h}$. After $24 \mathrm{~h}$ at $-20^{\circ} \mathrm{C}$, warming was continued at $+3{ }^{\circ} \mathrm{C} / \mathrm{h}$ to $+3^{\circ} \mathrm{C}$, and then the samples were maintained for $8 \mathrm{~h}$ at $+3{ }^{\circ} \mathrm{C}$ and subsequent $18 \mathrm{~h}$ at $+4{ }^{\circ} \mathrm{C}$.

For one of the cultured isolates (ECU-07), several modified substitution protocols were applied. Three different substitution media: (i) $2 \% \mathrm{OsO}_{4}$ in $100 \%$ acetone followed by $0.3 \% \mathrm{H}_{2} \mathrm{O}$; (ii) $2 \% \mathrm{OsO}_{4}$ in $100 \%$ acetone followed by $0.2 \%$ uranyl acetate; and (iii) $2 \% \mathrm{OsO}_{4}$ in $100 \%$ acetone followed by $1 \%$ thiocarbohydrazide in $\mathrm{H}_{2} \mathrm{O}$ for $5 \mathrm{~min}$ and then by $2 \% \mathrm{OsO}_{4}$ in $100 \%$ acetone (a so-called OTO method) were compared side-by-side. These methods were used to enhance membrane contrast and to achieve a better preservation of cellular structures (Willingham and Rutherford 1984). Subsequently, the specimens were rinsed three times with anhydrous acetone and infiltrated in a series of acetone: Epon resin mixes (2:1,1:1 and $1: 2$ for $1 \mathrm{~h}$ at each step at room temperature). After overnight incubation in pure Epon resin, material was released from the HPF carrier; whole specimen carriers were embedded in fresh Epon resin and polymerized for $48 \mathrm{~h}$ at $+62^{\circ} \mathrm{C}$. Ultrathin sections $(70 \mathrm{~nm})$ were cut using a UCT ultramicrotome (Leica Microsystems) and collected on copper grids, which were contrasted in ethanolic uranyl acetate and lead citrate, and observed in a JEOL 1010 TEM microscope (Jeol Europe) at an accelerating voltage of $80 \mathrm{kV}$. Images were captured using a Mega View III camera (Olympus Soft Imaging Solutions, Münster, Germany).

Bernhard's EDTA regressive staining was done according to the previously published protocols (Bernhard 1969, Gluenz et al. 2007). Thin sections were stained with $3 \%$ aqueous uranyl acetate for 10 min, washed in $\mathrm{H}_{2} \mathrm{O}$ and placed on a drop of 0.2 M EDTA, pH 7.0 for $15 \mathrm{~min}$. To control reversibility of staining, some sections were re-stained with $3 \%$ aqueous uranyl acetate. Before analysis, both uranyl acetate-stained and EDTA-bleached sections were treated for $1 \mathrm{~min}$ with lead citrate. Bernhard's EDTA regressive staining method (Bernhard 1969) can differentiate between the ribonucleoprotein and deoxyribonucleoprotein complexes, the former being resistant to EDTAdriven uranyl acetate removal (Moyne 1980).

\section{PCR amplification, cloning and sequencing}

Total genomic DNA was extracted from $10 \mathrm{ml}$ of the axenically grown cultures using High Pure PCR Template Preparation Kit (Roche Diagnostics, Mannheim, Germany) according to the manufacturer's protocol. For PCR amplification of the SL RNA gene repeat, the M167 and M168 primers (Westenberger et al. 2004) were used at amplification conditions published previously (Maslov et al. 2007). PCR products were cloned into the pGEM-T Easy Vector System (Promega, Madison, WI, USA) or pCR2.1 (Life Technologies, Carlsbad, CA, USA), and sequenced and analysed as described in Yurchenko et al. (2006a). The gGAPDH gene was PCR amplified using the M200 and M201 primers and the conditions according to Yurchenko et al. (2006a,b) and Maslov et al. (2010), and directly sequenced as described elsewhere (Votýpka et al. 2013).

The GenBank accession numbers for the new sequences determined in the course of this work are KF482057 (ECU-07 gGAPDH), KF482058 (ECU-08 gGAPDH), KF482059 (MMO09 gGAPDH), KF482060 (MCZ-11 gGAPDH), KF482061 (G15 gGAPDH), KF482062 (ECU-07 SL), KF482063 (ECU-08 SL), KF482064 (MMO-09 SL), and KF482065 (MCZ-11 SL), KF482066 (G15 SL).

\section{Phylogenetic analyses}

Phylogenetic analyses were performed as described earlier (Votýpka et al. 2012a,b, Týč et al. 2013). Briefly, only the most conserved section of the SL RNA repeats, starting at position -100 upstream of the exon and ending at the 3 ' end of the intron, were aligned by Clustal-X ver. 2.0 (Thompson et al. 2002) and used for species comparisons by neighbor joining clustering with K2P distances using PAUP* v4.b10 (Swofford 2001). The $90 \%$ cut-off level applied to the SL RNA sequence was used to delineate individual TUs (Maslov et al. 2007, 2013, Votýpka et al. 2010, 2012a).

The concatenated SSU rRNA and gGAPDH sequences were aligned by using Kalign (http://www.ebi.ac.uk/Tools/msa/kalign/) and the resulting alignments were edited manually using BioEdit 7.0.9.0 to remove the fast-evolving regions of SSU rRNA preventing unambiguous alignment. The final concatenated alignment included 3105 characters and the accession numbers of the gGAPDH, SSU rRNA, and SL RNA gene sequences retrieved from GeneBank and used in phylogenetic reconstructions are available upon request from authors.

Phylogenetic analyses of the SSU rRNA and gGAPDH datasets were performed with MrBayes 3.2.1 program (Ronquist et al. 2012) (Bayesian criteria: rates for six different types of substitution, proportion of invariant sites and shape parameter of the gamma correction for the rate heterogeneity with four discrete categories were allowed to vary; the covarion model was used to allow the rate heterogeneity along the tree; the Markov chain Monte Carlo was run for five million generations), PhyML for maximum likelihood (Guindon et al. 2009) (ML criteria: the best-fitting model GTR $+\mathrm{I}+\Gamma$ of the sequence evolution was searched using Modeltest 3.7 - Posada and Crandall 1998, and bootstrapped with 1000 replicates) and PAUP* v4.0b10 (Swofford 2001) for maximum parsimony (MP criteria: using ten replicates of heuristic search, $\operatorname{Tr} / \mathrm{Tv}$ ratio $1: 2$; the starting tree was obtained by the stepwise addition procedure with a random order of taxa addition and swapped using the tree bisection-reconnection algorithm and bootstrapped with 1000 replicates, each with ten replicates of random taxa addition with TBR branch swapping). 


\section{RESULTS}

\section{Isolation of four new trypanosomatid species}

The hosts of all four newly described trypanosomatid species belong to the Brachycera flies (Diptera) sampled in various countries: the strains ECU-07 and ECU-08 were obtained from the undetermined species of the genus Ravinia Robineau-Desvoidy (Sarcophagidae) and the undetermined species of the genus Eristalis Latreille (Syrphidae), respectively, captured in Otongatchi, Ecuador in 2008. The strain MMO-09 originated from Pachycerina vaga Adams (Lauxaniidae) sweep netted in Moramango, Madagascar in 2010 and the strain MCZ-11 was isolated from Cordilura albipes Fallén (Scathophagidae) captured in Prague Botanical Garden, Prague, Czech Republic in 2011. Phylogenetic analysis based on SSU rRNA of environmental samples obtained from these flies was presented elsewhere (Týč et al. 2013). It demonstrated that these organisms belong to different branches of monoxenous trypanosomatids and defined them as new TUs, i.e. potentially new species according to the previously described criteria for species discrimination (Westenberger et al. 2004, Maslov et al. 2013). The isolates ECU-07, ECU-08, MMO-09 and MCZ-11 were defined as TU110, TU104, TU105, and TU103, respectively.

All four strains are available in axenic cultures and the molecular analysis of their SL RNA gene repeats did not reveal any mixed infection (data not shown). The environmental samples MMO-09 and MCZ-11 were also monospecific (Týč et al. 2013). Importantly, for both ECU-07 and ECU-08, the organisms recovered in culture did not represent the parasites dominating the environmental samples obtained from the insect intestines (TU116/Angomonas desouzai Fiorini, 1989, and TU127, respectively) (Týč et al. 2013) as judged by their morphology and subsequent phylogenetic studies (see below). All four flagellates have been chosen for further molecular phylogenetic analysis, morphological characterization and ensuing formal taxonomic description.

\section{Morphological and ultrastructural characterization}

Examination of the ECU-07, ECU-08, MMO-09 and MCZ-11 axenic cultures by light and electron microscopy (Figs. 1-4) did not reveal any species-specific features, but the application of the HPF protocol proved suitable for the preservation of subtle or rarely observed ultrastructural features. As in several similar cases (Yurchenko et al. 2008, 2009, Maslov et al. 2010, Teixeira et al. 2011, Jirků et al. 2012, Borghesan et al. 2013), the unique SSU rRNA, gGAPDH, and SL RNA sequences represent the only reliable diagnostic characters. Nevertheless, to comply with established practices for formal species description, morphological description of the new isolates is presented below. Each of them exhibited features found in a typical trypanosomatid cell, e.g. oval nucleus, electron-dense kinetoplast disc in a reticulated mitochondrion rich with tubular cristae, singular flagellum supported by a paraxonemal rod, basal bodies, etc. The high resolution achieved with the HPF protocol allowed the observation of multiple viral particles in the cytosol of MMO-09 and even in the mitochondrion of MCZ-11 (see below).

\section{Phylogenetic analyses}

SL RNA sequence of ECU-07 (KF482062, $612 \mathrm{nt}$ ) was $85 \%$ homologous with a sequence obtained from 'Leptomonas' collosoma Wallace, Clark, Dyer et Collins, 1960 (S76723). Based on the $90 \%$ threshold rule (Maslov et al. 2007), it represents a separate typing unit (TU110) in agreement with previously published results (Týč et al. 2013). Sequences obtained from all three other isolates in this work - ECU-08 (KF482063, 262 nt), MMO-09 (KF482064, 886 nt), and MCZ-11 (KF482065, 854 nt) were homologous between 46 and $62 \%$, thus clearly representing separate typing units, defined as TU104, TU105, and TU103, respectively, as was shown elsewhere (Týč et al. 2013).

Judged from their SL RNA sequence similarity, the closest relative of ECU-08 is isolate G15 (TU83) from the true bug Rhynocoris rapax Stål (Heteroptera: Reduviidae) captured in Ghana in 2009, which is also available in culture (Votýpka et al. 2012a). Its SL RNA sequence was also determined in the course of this work and submitted to GenBank under the accession number KF482066. Moreover, Crithidia abscondita Maslov et Lukeš, 2009 isolate $127 \mathrm{AL}$, and Leptomonas scantii Votypka, Lukeš et Maslov, 2012 isolate F221 (Yurchenko et al. 2009, Votýpka et al. 2012b) group together with ECU-08.

MMO-09 shows similarity with several species and isolates described as Leptomonas, namely Leptomonas sp. isolate C4, L. podlipaevi Yurchenko, Lukeš, Xu et Maslov, 2006 and L. peterhoffi Podlipaev, 1985 (Podlipaev et al. 2004, Yurchenko et al. 2006b, 2009), whereas the strain MCZ-11 falls into the same TU (TU103) as an environmental isolate MCZ-04_envi from the brachyceran fly Coenosia albocornis Meigen (Muscidae) captured in Předboř, Czech Republic. This TU is close to Crithidia permixta Maslov et Lukeš, 2009 isolate 128SI (Yurchenko et al. 2009).

To better demonstrate phylogenetic relationships among the newly described and known trypanosomatids, a comprehensive SL RNA-based dendrogram has been built (Fig. 5). It revealed a close association of ECU-07 with the so-called 'collosoma' clade. In addition to the prototypical 'collosoma' species (see below), this group also includes an environmental isolate MCZ-09_envi (TU111) from the brachyceran fly of the family Lauxaniidae captured in Prague (Týč et al. 2013). The SL RNA sequences from axenic cultures of ECU-08, MMO-09, and MCZ-11 cluster within the clade recently ranked as the subfamily Leishmaniinae - Jirků et al. (2012).

As discussed above, the SL RNA gene repeat does not uphold sufficient phylogenetic signal and therefore can- 
not be used for inferring relationships between groups above the level of species/subspecies complexes. In practice it means that unreliable or not highly supported branches must be confirmed independently using other genetic markers. The SSU rRNA + gGAPDH-based phylogeny shown in Fig. 6 correlates very well with the SL RNA-based reconstruction presented in Fig. 5 and with previously published data on environmental and selected cultured isolates (Týč et al. 2013). Three isolates, ECU08, MMO-09 and MCZ-11, show affinities to different clades (potential genera) within the subfamily Leishmaniinae (see Taxonomic summary). Two isolates, ECU-08 and MCZ-11 match well with two different groups represented mainly by species of Crithidia, whereas MMO09 clusters together with several previously described isolates of the genus Leptomonas, which is most closely related to Leishmania. However, phylogenetic position of MMO-09 is not very stable. Importantly, in all phylogenetic reconstructions, the isolate ECU-07 groups within the previously described 'collosoma' clade (see Taxonomic summary and discussion).

Class Kinetoplastea Honigberg, 1963 emend. Vickerman, 1976

Subclass Metakinetoplastina Vickerman, 2004

Order Trypanosomatida Kent, 1880

Family Trypanosomatidae Doflein, 1901

Wallaceina Podlipaev, Frolov et Kolesnikov, 1999, emend. Votýpka, Yurchenko et Lukeš, 2014

Synonym: Proteomonas Podlipaev, Frolov et Kolesnikov, 1990 (preoccupied).

Emended generic diagnosis: A well-supported monophyletic group of monoxenous trypanosomatids of invertebrate hosts (e.g. Heteroptera and Diptera) without bacterial endosymbionts. It is defined by a set of unique sequences of SSU, gGAPDH and SL RNA genes. Molecular phylogenetic analyses confirm this genus as a member of the family Trypanosomatidae; however, it cannot be associated with any valid genera of either monoxenous or dixenous trypanosomatids. Characteristic for the genus Wallaceina, namely the presence of endomastigotes described in the previous generic description (Podlipaev et al. 1990, Bulat et al. 1999), is no longer valid as a diagnostic feature of the genus; however, this morphotype could be encountered in situ or in culture.

Remarks. The genus Wallaceina was introduced by Podlipaev, Frolov et Kolesnikov in 1999 in honor of Dr. F.G. Wallace. They proposed this nomen novum to replace the previous generic name Proteomonas erected by the same authors, Podlipaev, Frolov and Kolesnikov in 1990. The original name Proteomonas represents a junior homonym of Proteomonas Hill et Wetherbee, 1986, a marine cryptophyte (Podlipaev et al. 1990, Bulat et al. 1999, Podlipaev and Frolov 2000). In addition to the type species, Wallaceina inconstans (Podlipaev, Frolov et Kolesnikov, 1990), several other species have been assigned to the genus Wallaceina due to the presence of endomastigotes in the culture - Wallaceina brevicula (Podlipaev, Frolov et Kolesnikov, 1990), Wallaceina podlipaevi (Podlipaev, 1985), and Wallaceina vicina Malysheva et Frolov, 2004. Subsequent molecular analysis of available axenic cultures of the above-mentioned species has demonstrated that these trypanosomatids represent different groups of the family Trypanosomatidae (Bulat et al. 1999, Merzlyak et al. 2001, Kostygov et al. 2004, Malysheva and Frolov 2004, 2009). Most of them clustered together within the subfamily Leishmaniinae, the prominent exception being Wallaceina sp. Wsd, which was found to be a member of the 'collosoma' clade (Podlipaev et al. 2004).

\section{Survey of species}

\section{(i) Currently valid, non-cultivated species:}

(1) Wallaceina inconstans (Podlipaev, Frolov et Kolesnikov, 1990) isolated from Calocoris sexguttatus Wagner (Heteroptera), White Sea coast, North-West Russia. This is the type species of Wallaceina.

Remarks. The available axenic cultures and sequences assigned to Wallaceina inconstans (AF153044, EU088282, EU088281, EU088280, EU076608, AJ401356, AJ401382, AF124056, and AF121798) may represent another species.

(2) Wallaceina brevicula (Podlipaev, Frolov et Kolesnikov, 1990) isolated from Nabis brevis Scholtz (Heteroptera), White Sea coast, North-West Russia.

Remarks. The available axenic cultures and sequences assigned to Wallaceina brevicula (AF153045, EU088279, EU088278, EU088277, AF316620, AJ401357, Z32854, and AJ401378) may represent another species.

(3) Wallaceina podlipaevi (Podlipaev, 1985) isolated from Nabicula flavomarginata Scholtz (Heteroptera), North-West Russia.

Remarks. The available axenic cultures and sequences assigned to Wallaceina podlipaevi (JN944133) may represent another species.

(4) Wallaceina vicina Malysheva et Frolov, 2004 isolated from Gerris rufoscutellatus Latreille (Heteroptera), North-West Russia.

Remarks. The available axenic cultures assigned to Wallaceina vicina may represent another species.

Remarks. All these species belong to the genus Wallaceina based on their original morphological descriptions (e.g. presence of endomastigotes). Upon prolonged cultivation, this morphotype was effectively substituted by better adapted promastigotes of Leptomonas or Crithidia species of the subfamily Leishmaniinae.

The isolate Wallaceina sp. Wg of Malysheva and Frolov (2004) was isolated from Gerris rufoscutellatus (Heteroptera) in North-West Russia and classified as Wallacei$n a$ based on its morphology. Endomastigotes predominant during the isolate description were lost during cultivation. 
The available axenic cultures assigned to Wallaceina $\mathrm{sp}$. Wg may represent another species.

\section{(ii) New combinations}

(5) Wallaceina (Leptomonas) collosoma (Wallace, Clark, Dyer et Collins, 1960) Votýpka, Yurchenko et Lukeš, comb. n. This species corresponds to former Leptomonas collosoma isolated from Gerris dissortis Drake et Harris (Heteroptera), Minneapolis, USA.

(6) Wallaceina (Leptomonas) rigida (Podlipaev, Malysheva et Kolesnikov, 1991) Votýpka, Yurchenko et Lukeš, comb. n. This species corresponds to former Leptomonas rigidus isolated from Salda littoralis Linnaeus.

(Heteroptera), White Sea coast, North-West Russia.

Remarks. Both species are available in culture and belong to the genus Wallaceina based on their phylogenetic position. Wallaceina sp. Wsd, isolated by S. Podlipaev from Salda littoralis (Heteroptera), White Sea coast, North-West Russia, and available in culture, represents another member of this genus.

\section{(iii) New species}

Wallaceina raviniae Votýpka et Lukeš sp. n.

Fig. 1

Species diagnosis: Cells of Wallaceina raviniae typical oval-shaped choanomastigotes, 4.7-8.6 (6.2 \pm 0.7 , i.e. mean $\pm \mathrm{SD} ; \mathrm{n}=50)$ long and 1.7-4.7 (3.2 $\pm 0.5 ; \mathrm{n}=50)$ wide. Larger promastigotes less abundant $6.2-10.5$ in length $(8.7 \pm 0.7 ; \mathrm{n}=29), 1.5-3.5$ in width $(2.5 \pm 0.3$; $\mathrm{n}=29$ ), endomastigotes very rare. Flagella ranges $3.6-12.1(8.2 \pm 2.5 ; \mathrm{n}=50)$ long in choanomastigotes, and $8.3-16.0(12.4 \pm 1.2 ; \mathrm{n}=29)$ in promastigotes and promastigote-like forms. Ratio of length of flagellum per length of cells almost constant (1.3 to 1.4) in all morphotypes analysed.

Distance from kinetoplast to anterior end of cell 1.3-4.3 (2.9 $\pm 0.7 ; \mathrm{n}=50)$ in choanomastigotes and $1.3-3.5(2.1 \pm 0.4 ; \mathrm{n}=29)$ in promastigotes. Multiple acidocalcisomes, dispersed rather regularly throughout cytoplasm appear prominently stained in Giemsa smears. Kinetoplast 300-700 nm $(486 \pm 120 \mathrm{~nm} ; \mathrm{n}=21)$ in length and $90-200 \mathrm{~nm}(134 \pm 29 \mathrm{~nm} ; \mathrm{n}=21)$ in width. Flagellar pockets filled with highly abundant helically structured electron dense material.

The species is identified by the unique sequences with the following GenBank accession numbers: KC205996 (SSU), KF482057 (gGAPDH) and KF482062 (SL), and belongs to TU110.

Type host: Fly Ravinia sp. (Diptera: Brachycera: Sarcophagidae), female. Xenotype (2008/E-DIPT07/M) deposited at Charles University, Prague.

S i t e : Intestine (hindgut: rectal ampulla).

Type 1 oc ality: Vicinity of Otongatchi, western edge of the Cloud forest $\left(00^{\circ} 19^{\prime} 35.3^{\prime \prime} \mathrm{S} ; 7^{\circ} 55^{\prime} 19.5^{\prime \prime} \mathrm{W}\right)$, Ecuador.

Type material: Hapantotype (Giemsa-stained slide 2008/E-DIPT07/S) and axenic culture (ECU-07) deposited at Charles University, Prague.

Etymology: The species name is a feminine derived from the name of the fly host (Ravinia sp.).

Remarks. The overall morphology of $W$. ravinae is very similar to that of $W$. collosoma comb. $\mathrm{n}$. isolated in the 1960's from a true bug (Heteroptera) of the genus Gerris Fabricius (Wallace et al. 1960) and W. rigida from another true bug, Salda littoralis (see Podlipaev et al. 1991).

Subfamily Leishmaniinae Maslov et Lukeš, 2012

Crithidia otongatchiensis Votýpka et Lukeš sp. n. Fig. 2

Species diagnosis: Majority of cultured Crithidia otongatchiensis cells typical choanomastigotes with no species-specific diagnostic features discernible by light or electron microscopy; 4.3-7.3 $(6.1 \pm 0.5)$ in length and $2.6-5.0(3.7 \pm 0.4 ; \mathrm{n}=50)$ in width, with flagella 5.5-13.7 $(10.2 \pm 1.4 ; \mathrm{n}=50)$. Minor promastigote-like morphotype represented by cells $8.7-11.0(9.6 \pm 0.5 ; \mathrm{n}=18)$ long and $1.8-3.8(2.9 \pm 0.3 ; \mathrm{n}=18)$ wide, with flagellum 7.5-14.3 $(10.9 \pm 2.2 ; n=18)$ long. Average ratio of length of flagellum to length of cells approximately 1.7 for choanomastigotes and 1.1 for promastigotes. Pre-nuclear kinetoplast is positioned within 0.2 to $2.4(1.3 \pm 0.5 ; \mathrm{n}=50)$ in choanomastigotes and within 1.5 to $4.3(2.4 \pm 0.8 ; \mathrm{N}=18)$ in promastigotes from the nucleus.

Distance from kinetoplast to anterior end of cell 1.6-3.7 $(2.2 \pm 0.3 ; \mathrm{n}=50)$ in choanomastigotes and 1.5-3.6 (2.5 $\pm 0.4 ; \mathrm{n}=18)$ in promastigotes. Acidocalcisomes are detectable in Giemsa-stained smears. Kinetoplast densely packed disc 450-900 nm $(652 \pm 122 \mathrm{~nm} ; \mathrm{n}=15)$ long and 290-400 nm (337 $\pm 39 \mathrm{~nm} ; \mathrm{N}=15)$ wide.

The species is identified by the unique sequences with the following GenBank accession numbers: KC205989 (SSU), KF482058 (gGAPDH) and KF482063 (SL), and belongs to TU104.

Type host: Fly Eristalis sp. (Diptera: Brachycera: Syrphidae), male. The xenotype (2008/E-DIPT08/M) is deposited at Charles University, Prague.

$\mathrm{S}$ ite: Intestine (midgut: mesenteron; inside the peritrophic matrix).

Ty pe loc a lity: Vicinity of Otongatchi, western edge of the Cloud forest $\left(00^{\circ} 19^{\prime} 35.3^{\prime \prime S}\right.$; 78 55'19.5"W), Ecuador.

Type material: Hapantotype (Giemsa-stained slide 2008/E-DIPT07/S) and axenic culture (ECU-08) deposited at Charles University, Prague.

Etymology: The species name is a noun in apposition adopting the name of the type locality.

Remarks. The new species is ascribed to the polyphyletic genus Crithidia based on predominance of choanomastigotes. The distinguishing features of this species are very prominent unpolarized Golgi apparatus and large mitochondria with extremely high number of cristae, cross-sectioned multiple times, especially at the periphery of the organelle. Based on gGAPDH (KF482061), 

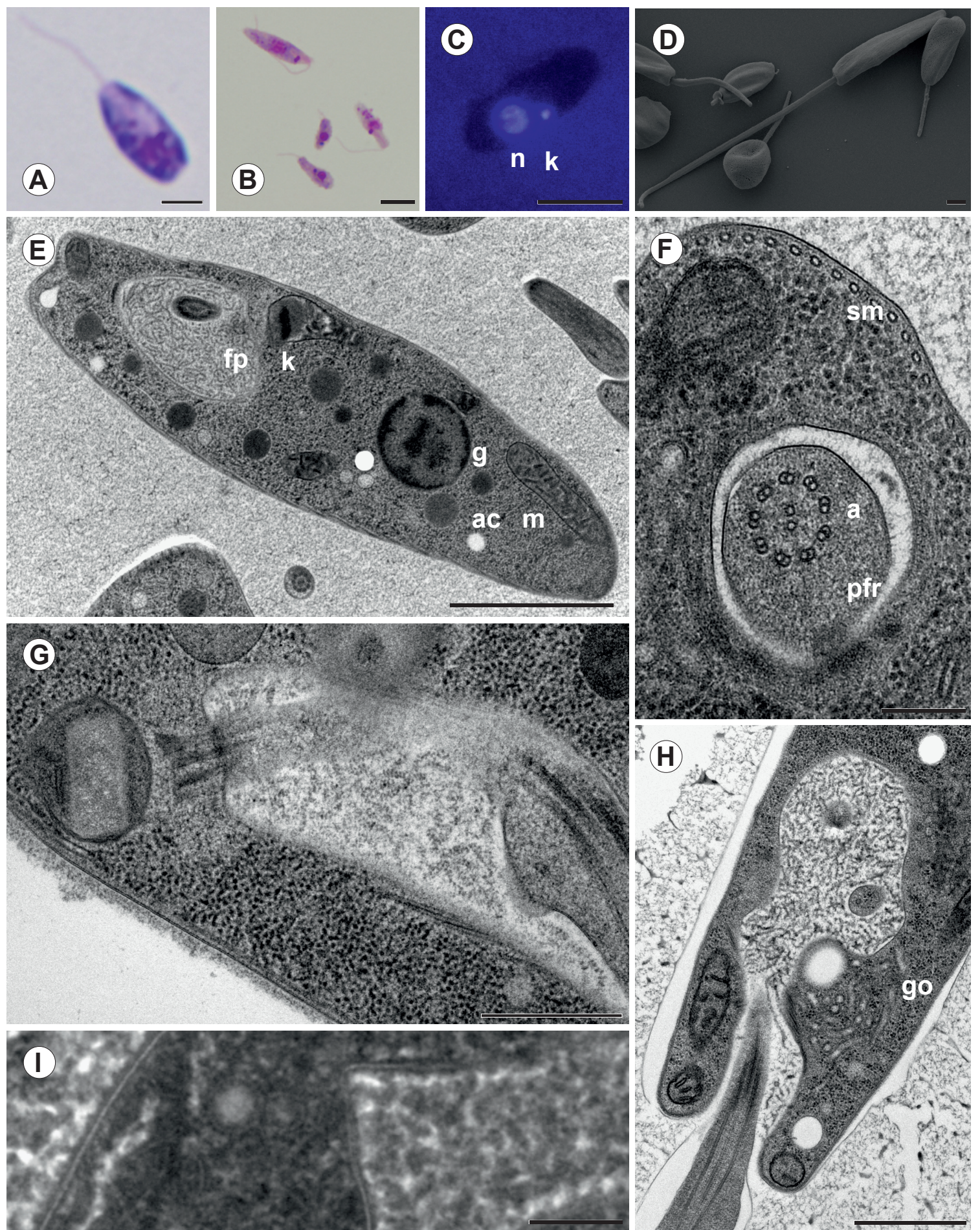

Fig. 1. Wallaceina raviniae sp. n. from Ravinia $\mathrm{sp}$. A, B - Giemsa-stained cultured cells; C-DAPI-stained cultured cells. Note kinetoplast (either pre- or postnuclear) located in close proximity $(0.8 \pm 0.5 \mu \mathrm{m} ; \mathrm{N}=50)$ to the nucleus in choanomastigotes. $\mathbf{D}-\mathrm{scanning}$ electron microscopy demonstrates different morphotypes in culture; $\mathbf{E}-\mathbf{I}$-transmission electron microscopy; $\mathbf{F}$ - cross-section of the flagellar pocket allows visualization of the $9+2$ axoneme and the paraflagellar rod that is characteristically inconspicuous within the flagellar pocket, but enlarged in the emerging part of the flagellum, as $\mathbf{H}$ - visualized in the longitudinal section. Abundant helically structured electron dense material fills in flagellar pockets. This material is highly reminiscent of filamentous phosphoglycoprotein polymers of secreted acid phosphatase. G - Bernhard's EDTA regressive staining method was used to 'bleach' the kDNA disk; I - osmium-thiocarbohydrazide-osmium (OTO) method was employed to enhance membrane contrast. Abbreviations: a - axoneme; ac - acidocalcisomes; fp - flagellar pocket; g - glycosomes; go - Golgi apparatus; $\mathrm{k}$ - kinetoplast; $\mathrm{m}$ - mitochondrion; $\mathrm{n}$ - nucleus; pfr - paraflagellar rod; sm - subpellicular microtubules. Scale bars: A,E $=2 \mu \mathrm{m} ; \mathrm{B}, \mathrm{C}=5 \mu \mathrm{m} ; \mathrm{D}, \mathrm{H}=1 \mu \mathrm{m} ; \mathrm{F}=200 \mathrm{~nm}, \mathrm{G}=500 \mathrm{~nm}$, $\mathrm{I}=125 \mathrm{~nm}$. 

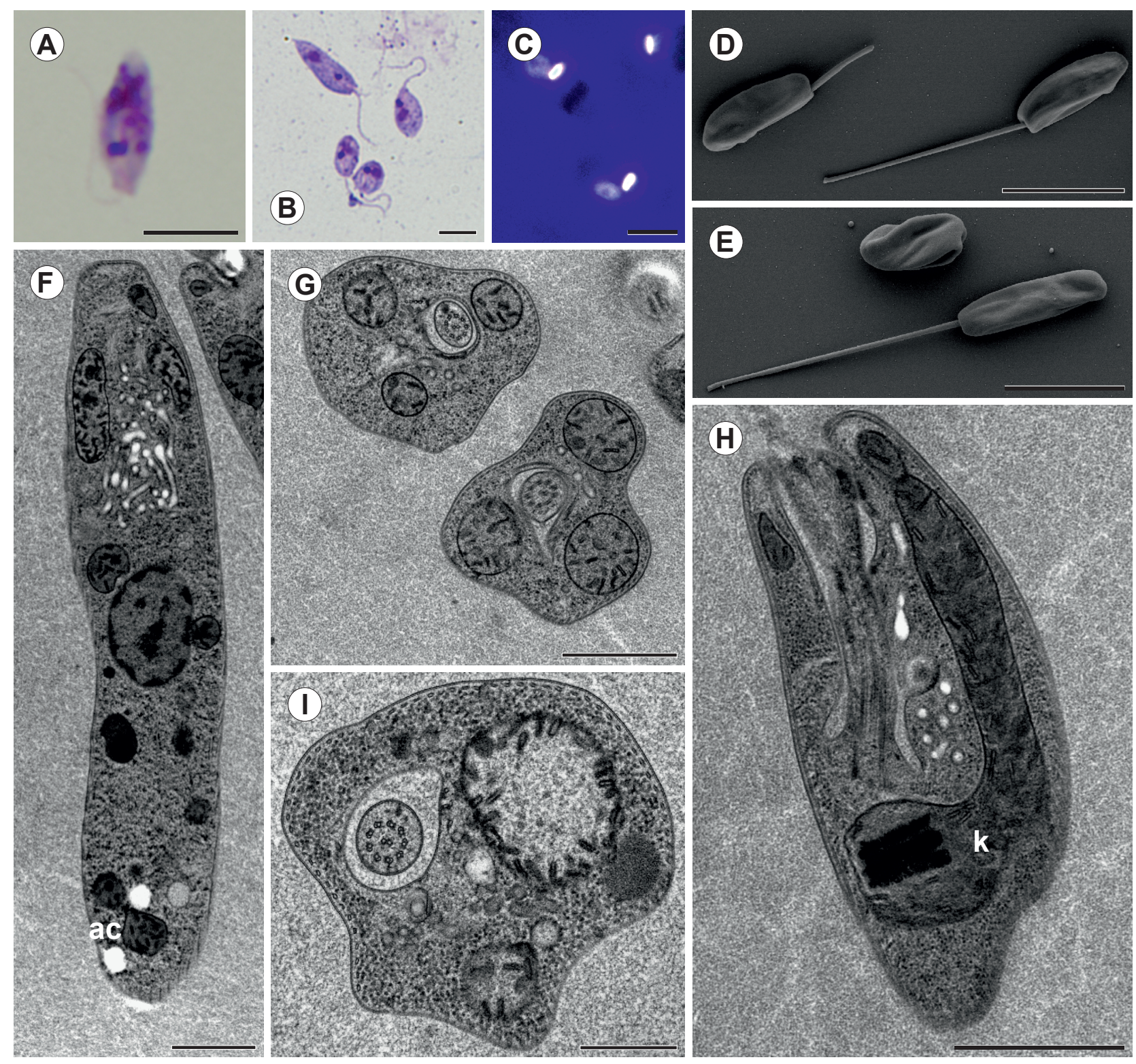

Fig. 2. Crithidia otongatchiensis sp. n. from Eristalis sp. A, B - Giemsa-stained cultured cells; C - DAPI-stained cultured cells with well-visible kinetoplast (intensely stained oval spot) and nucleus; $\mathbf{D}, \mathbf{E}$ - several distinct morphotypes from choano- to grooved spade-shaped and sometimes twisted promastigotes with flagella of various lengths including some cells lacking a visible flagellum are detectable by SEM; F-I - transmission electron microscopy; F - unusually large Golgi apparatus and acidocalcisomes; G, I - extended mitochondrion with multiple cristae; $\mathbf{H}$ - kinetoplast and numerous vesicles associated with the flagellar pocket. Abbreviations: ac - acidocalcisomes; $\mathrm{k}$ - kinetoplast. Scale bars: A-E $=5 \mu \mathrm{m} ; \mathrm{F}-\mathrm{H}=1 \mu \mathrm{m} ; \mathrm{I}=500 \mathrm{~nm}$.

SL (KF482066) and SSU (JQ658813) sequences, the isolate G15 (TU83) from the hindgut of Rhynocoris rapax (Heteroptera: Reduviidae) captured in the vicinity of Maste (06³9'22"N; 00³0'53"E) (Votýpka et al. 2012a) is a close relative of $C$. otongatchiensis.

Leptomonas moramango Votýpka et Lukeš sp. n. Fig. 3

Species diagnosis: Cells of Leptomonas moramango typical promastigotes with limited heterogeneity, 7.9-11.4 $(10.2 \pm 0.7 ; \mathrm{n}=50)$ long and 2.1-4.4 (3.2 $\pm 0.3 ; \mathrm{n}=50)$ wide. Flagellum 4.9-13.0 (7.5 $\pm 0.9 ; \mathrm{n}=50)$ long. Average ratio of length of flagellum to length of cells about 0.9 .
Prenuclear kinetoplast located $0.9-5.8(2.1 \pm 1.2 ; \mathrm{n}=50)$ from nucleus.

Distance from kinetoplast to anterior end of cell 1.3-3.3 $(2.0 \pm 0.4 ; \mathrm{n}=50)$. Multiple acidocalcisomes detectable in Giemsa-stained smears. Irregularly shaped flagellumassociated structure often seen at flagellum pocket opening. Kinetoplast disc length 570-1 $100 \mathrm{~nm}(826 \pm 144 \mathrm{~nm}$; $\mathrm{n}=23)$, width 100-220 nm $(147 \pm 29 \mathrm{~nm} ; \mathrm{n}=23)$.

The species is identified by the unique sequences with the following GenBank accession numbers: KC205990 (SSU), KF482059 (gGAPDH) and KF482064 (SL), and belongs to TU105. 

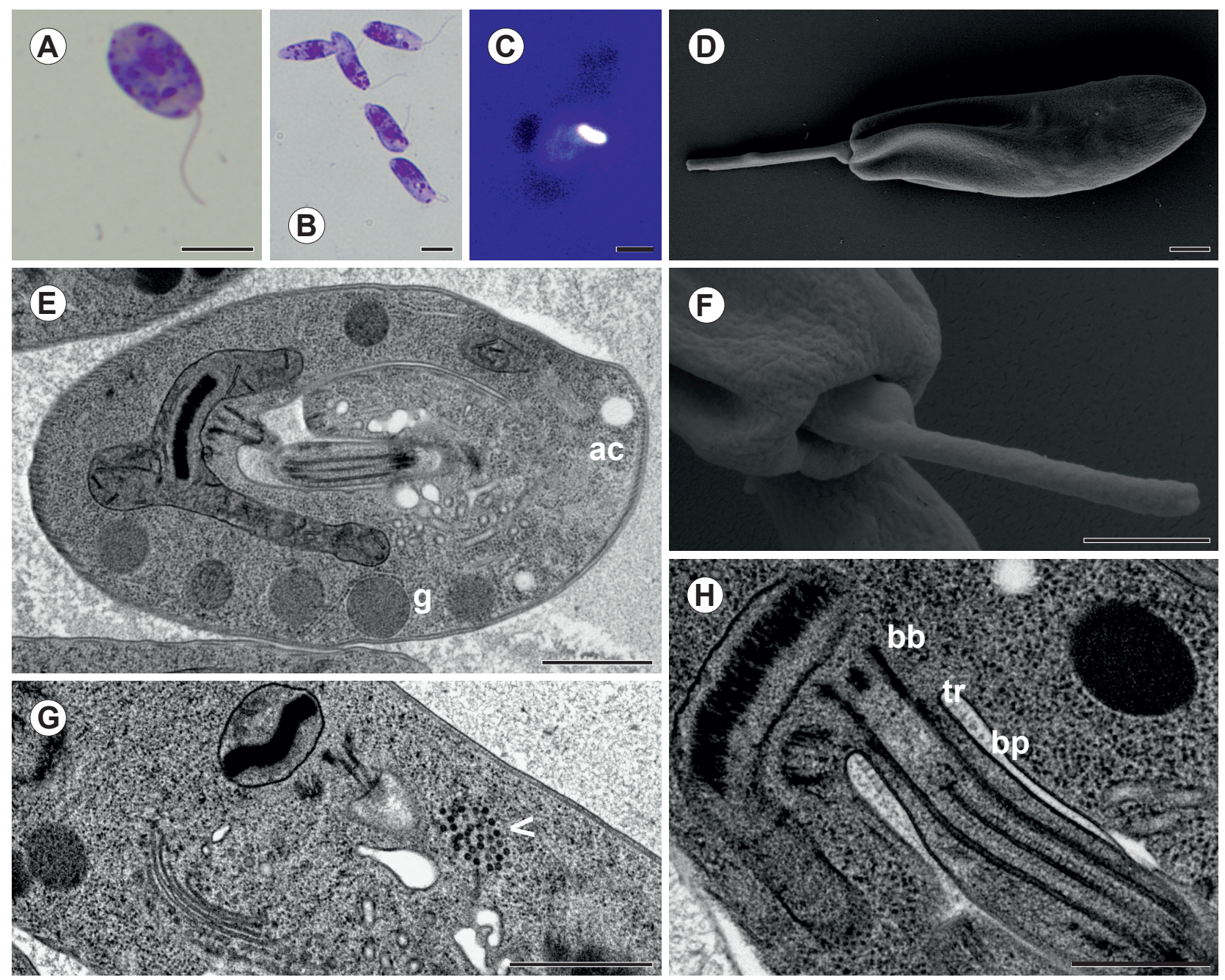

Fig. 3. Leptomonas moramango sp. n. A, B - Giemsa-stained cultured promastigotes; C - DAPI-stained cultured promastigotes with well-visible trypanosomatid-specific features, such as compact kinetoplast and acidocalcisomes; D, F - SEM shows typical promastigote morphology with irregularly shaped flagellum-associated bulge at the emergence of the flagellum from the flagellar pocket; E - TEM demonstrates presence of glycosomes, acidocalcisomes, numerous flagellar pocket-associated vesicles and other standard cellular features; $\mathbf{G}$ - group of cytoplasmic viruses is marked with an arrowhead; $\mathbf{H}$ - fine structure of the axoneme. Abbreviations: ac - acidocalcisomes; bb - basal body; bp - basal plate; $\mathrm{g}$ - glycosomes; $\operatorname{tr}$ - transition region Scale bars: $\mathrm{A}, \mathrm{B}=5 \mu \mathrm{m} ; \mathrm{C}=2 \mu \mathrm{m}$; $\mathrm{D}-\mathrm{G}=1 \mu \mathrm{m} ; \mathrm{H}=500 \mathrm{~nm}$.

Type host: Fly Pachycerina vaga (Brachycera: Lauxaniidae), female. The xenotype (2010/Mg-MMO-09/M) is deposited at Charles University, Prague.

S i te : Intestine (hindgut: rectal ampulla).

Type locality: Vicinity of Moramango (18 $55^{\prime} 34.9^{\prime \prime} \mathrm{S}$; $\left.48^{\circ} 25^{\prime} 4.3^{\prime \prime} \mathrm{E}\right)$, Madagascar.

Type material: Hapantotype (Giemsa-stained slide 2010/ Mg-MMO-09/S) and axenic culture (MMO-09) deposited at Charles University, Prague.

Etymology: The species name is a noun in apposition adopting the name of the type locality.

Remarks. The new species is ascribed to the polyphyletic genus Leptomonas based on predominance of promastigotes. The distinguishing features of this species are very prominent unpolarized Golgi apparatus and multiple periflagellar vesicles. Leptomonas moramango can be infected with cytosolic viruses.
Crithidia pragensis Votýpka, Klepetková et Lukeš sp. n.

Fig. 4

Species diagnosis: Most of Crithidia pragensis cells oval-shaped choanomastigotes 5.7-10.1 (7.5 \pm 0.6 ; $\mathrm{n}=50)$ long and $2.8-5.9(4.5 \pm 0.6 ; \mathrm{n}=50)$ wide. Flagella 5.5-20.2 $(13.7 \pm 2.5 ; \mathrm{n}=50)$ long, exceeding almost twice length of cell. Kinetoplast always prenuclear, located $0.2-4.1(1.7 \pm 0.7 ; n=50)$ from nucleus and 0.7-4.0 $(2.1 \pm 0.6 ; \mathrm{n}=50)$ from anterior end of the cell. Giemsastained round and equally-sized acidocalcisomes prominently visible. Kinetoplast 420-1250 nm (780 $\pm 201 \mathrm{~nm}$; $\mathrm{n}=17)$ long and 170-360 (223 $\pm 43 \mathrm{~nm} ; \mathrm{n}=17)$ wide.

The species is identified by unique sequences with the following GenBank accession numbers: KC205988 (SSU), KF482060 (gGAPDH) and KF482065 (SL), and belongs to TU103. 

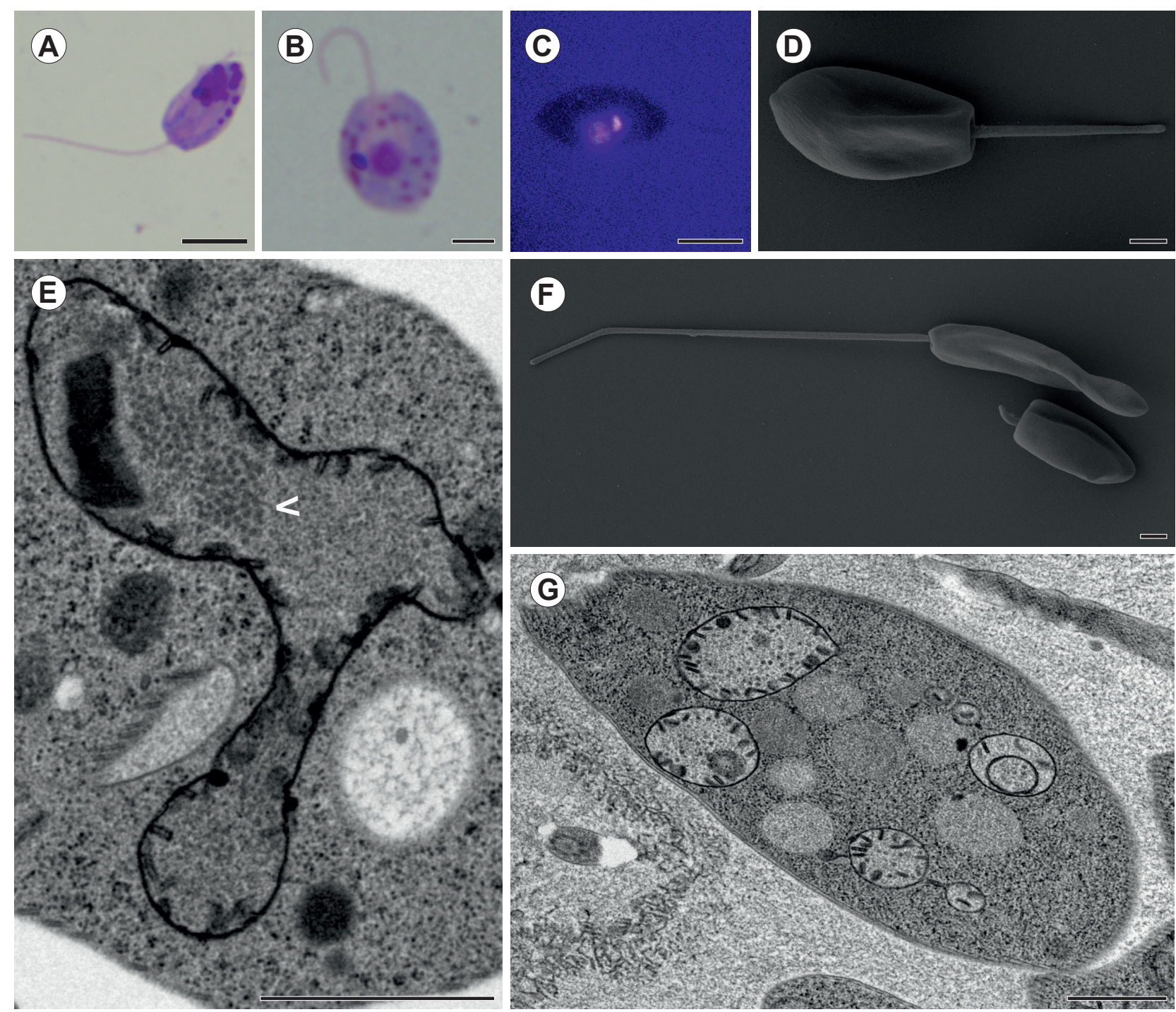

Fig. 4. Crithidia pragensis sp. n. from Cordilura albipes A, B - Giemsa-stained cultured choanomastigotes; C - DAPI-stained cultured choanomastigotes with typical intracellular structures of Trypanosomatidae, DAPI staining reveals the position of the kinetoplast adjacent to the nucleus. D, F - scanning electron micrographs illustrate extensive variability in flagellar length. $\mathbf{E}-\mathrm{a}$ group of virus-like particles (arrowhead) in the mitochondrial lumen; $\mathbf{G}$ - unusually high number of peripherally-located cristae. Scale bars: $\mathrm{A}, \mathrm{C}=5 \mu \mathrm{m} ; \mathrm{B}=2 \mu \mathrm{m} ; \mathrm{D}-\mathrm{G}=1 \mu \mathrm{m}$.

Ty p e host: Fly Cordilura albipes (Brachycera: Scatophagidae), female. The xenotype (2011/Cz-MCZ-11/M) is deposited at Charles University, Prague.

S i t e : Intestine (hindgut).

Type locality: Prague, Botanical Garden $\left(50^{\circ} 03^{\prime} 64.7^{\prime \prime} \mathrm{N}\right.$; $\left.14^{\circ} 22^{\prime} 51.5^{\prime \prime} \mathrm{E}\right)$, Czech Republic.

Type material: Hapanotype (Giemsa-stained slide 2011/ $\mathrm{Cz}-\mathrm{MCZ}-11 / \mathrm{S})$ and axenic culture (MCZ-11) deposited at Charles University, Prague.

Etymology: The species name is derived from the name of the type locality.

Remarks. The new species is ascribed to the polyphyletic genus Crithidia based on predominance of choanomastigotes. The distinguishing feature of this species is high number of predominantly peripheral mito- chondrial cristae. C. pragensis can be infected with viruses localized to mitochondrion. Based on the environmental SSU sequence (KC205984), the isolate (MCZ-04_envi) from brachyceran fly Coenosia albocornis Meigen (Muscidae) captured in Předboŕ, Czech Republic belongs to the same TU (TU103) and thus represents another strain of C. pragensis.

\section{DISCUSSION}

In last decades, many studies have documented a rather confusing situation in the systematics of the Trypanosomatidae. While some genera have been confirmed to be monophyletic, others have remained poorly defined and polyphyletic (Maslov et al. 1996, 2001, 2013, Hollar et al. 1998), and the rest was redefined, re-erected or 


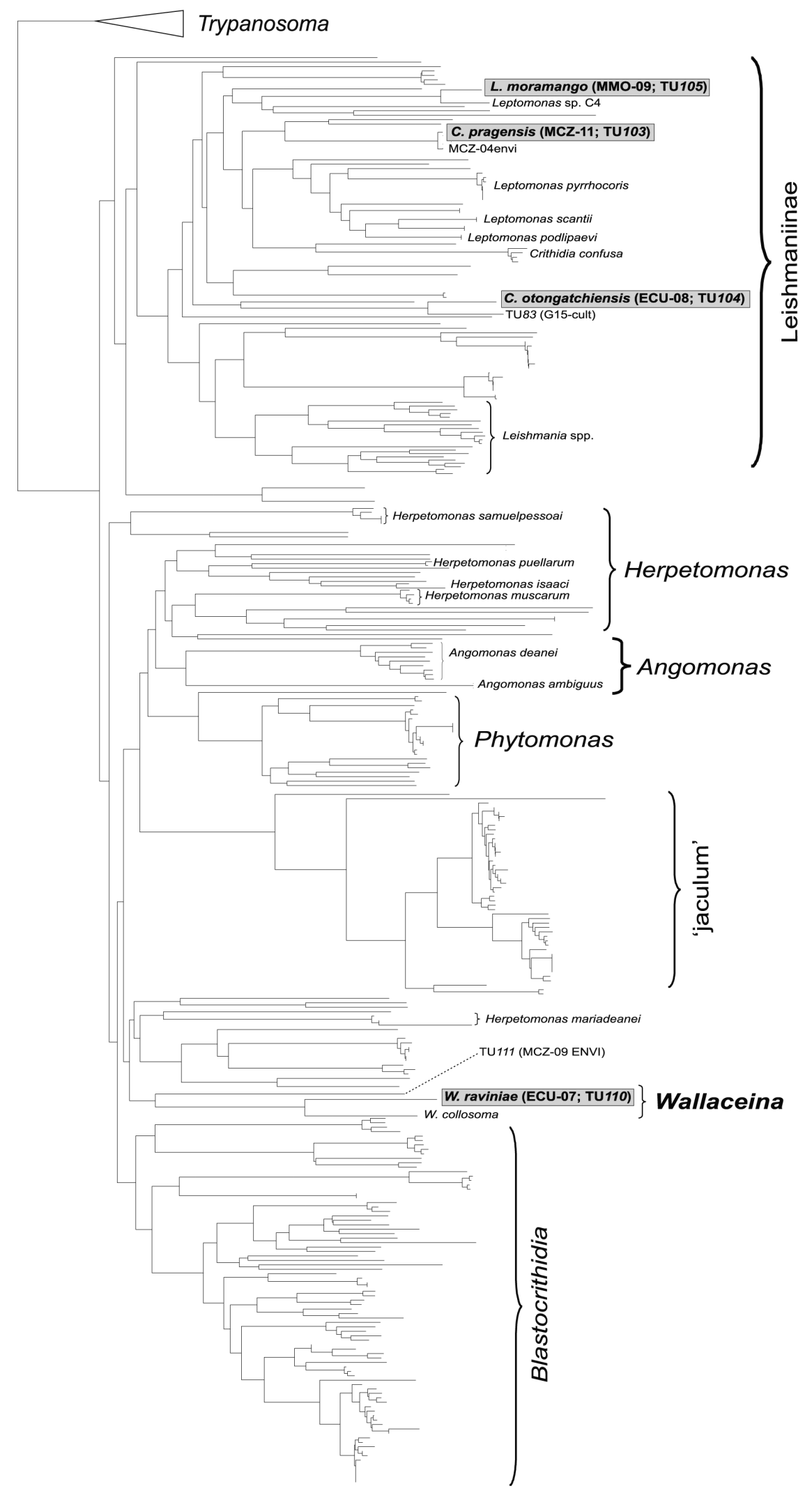

Fig. 5. The dendrogram of splice-leader (SL) sequences. Neighbor-joining analysis of the SL RNA gene repeats of Trypanosomatidae emphasizing the phylogenetic position of species described in this work. The most conserved region (from ' -100 'nt position upstream of the exon to the 3 ' end of the intron, excluding the amplification primer sequences) was selected and aligned with Clustal $\mathrm{X}$. Sequence alignments and GenBank accession numbers for the retrieved sequences are available from authors upon request. 


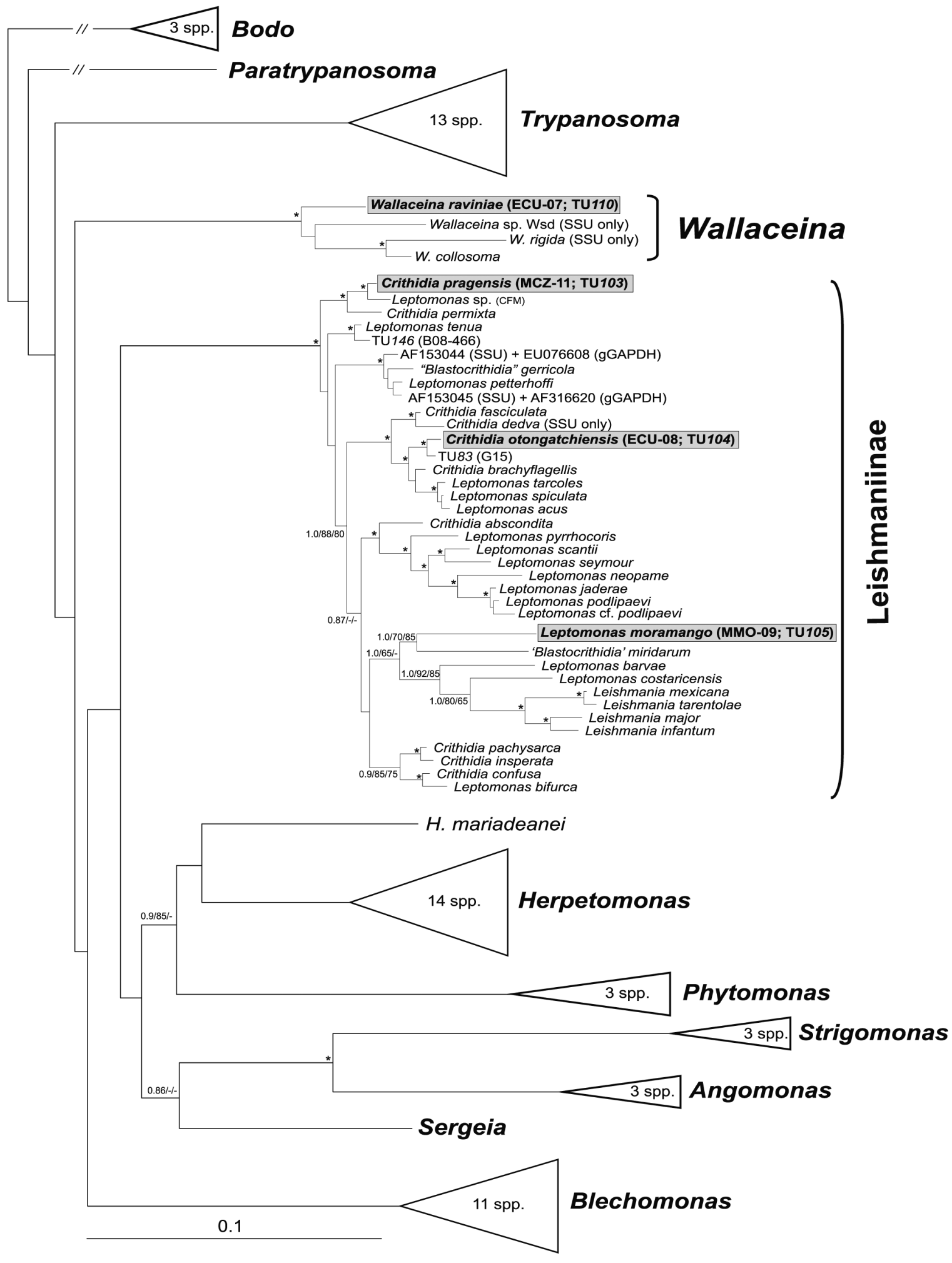

Fig. 6. SSU rRNA + gGAPDH-based Bayesian phylogenetic tree of Trypanosomatidae. Names of species for sequences retrieved from GenBank are indicated. Species newly described in this work (highlighted) are accompanied by original name of the isolates and designated typing unit (in parentheses). Bootstrap values from Bayesian posterior probabilities (5 million generations), maximum parsimony and maximum likelihood (1000 replicates) are shown at the nodes. Asterisks denote Bayesian posterior probabilities and bootstraps of $95 \%$ or higher; dashes indicate bootstrap support below $50 \%$ or Bayesian posterior probability below 0.5 or different topology. The tree was rooted with three bodonid sequences. The scale bar denotes the number of substitutions per site. The GenBank accession numbers for the SSU rRNA and gGAPDH sequences used here are available from authors upon request. 
newly described (Svobodová et al. 2007, Jirků et al. 2012, Borghesan et al. 2013). Although more than 50\% of the monoxenous trypanosomatids were described from true bugs, recent studies on the biodiversity of dipteran parasites demonstrate their association with different clades of monoxenous trypanosomatids including those occupied mainly by parasites of Heteroptera (Týč et al. 2013).

In this regard, two seemingly unrelated cases which, as shown below, are two sides of the same problem, deserve special attention. The first case is represented by the phylogenetically well-defined group referred to as the 'collosoma' clade (Maslov et al. 2013), its original name being derived from 'Leptomonas' collosoma - see (Wallace et al. 1960). By all accepted standards of that time, this species was classified as yet another representative of the genus Leptomonas mainly because of its prototypical promastigote morphology (Wallace 1966). It is also worth noticing that this organism became a proxy of the model system for biochemical and molecular studies of the monoxenous trypanosomatids (Harris et al. 1995, Mandelboim et al. 2002). However, phylogenetic analyses convincingly demonstrated that this species is quite different from the majority of Leptomonas species, which have been recently accommodated into the subfamily Leishmaniinae (Jirků et al. 2012). 'Leptomonas' collosoma along with a few other species and unnamed isolates formed a separate clade branching off from the rest of the trypanosomatids (Týč et al. 2013).

The second case is represented by the genus Wallacei$n a$. The apomorphic character used to define this genus was the presence of endomastigotes both in situ and in vitro, and $W$. inconstans was defined as its type species (Podlipaev 1990, Podlipaev et al. 1990). Over the years, a few additional members of this group, for example Wallaceina $\mathrm{sp}$. Wsd and $\mathrm{Wg}, W$. vicina, and $W$. podlipaevi were described (Kostygov et al. 2004, Malysheva and Frolov 2004, 2009, Podlipaev et al. 2004). The discordance between the traditional and molecular-based systematics became apparent when members of this genus have shown different phylogenetic attractions. Wallaceina inconstans, $W$. brevicula, $W$. podlipaevi and $W$. vicina formed a separate clade within the subfamily Leishmaniinae along with Leptomonas tenua Maslov et Lukeš, 2012, Crithidia permixta and several unnamed 'leptomonad' isolates from the nematoceran fly (Jirků et al. 2012, Týč et al. 2013; J.V. - unpubl. data; A. Kostygov, University of Ostrava - pers. comm.), whereas Wallaceina sp. Wsd grouped together with 'Leptomonas' collosoma and 'Leptomonas' rigida. To complicate this matter even further, the original culture of the type species, $W$. inconstans, on which the morphological diagnostics has been based, was found to represent a mixed population of at least two trypanosomatid isolates (Yurchenko et al. 2008). It was speculated that the originally dominant Wallaceina species containing typical endomastigotes might have been steadily substituted by faster growing cells represented by typical leptomonad promastigotes belonging to the subfamily Leishmaniinae (Jirků et al. 2012).

In this study we describe four new monoxenous species of the family Trypanosomatidae and amend the genus Wallaceina. We suggest using this taxon name for a genus uniting species of the former 'collosoma' clade: Wallaceina (formerly Leptomonas) collosoma, Wallaceina (formerly Leptomonas) rigida, and Wallaceina ravinia sp. $\mathrm{n}$. The strain Wsd (designated as Wallaceina in some studies - Kostygov et al. 2004, Gerasimov et al. 2012) represents another so far unnamed Wallaceina species. Wallaceina inconstans, $W$. brevicula, $W$. podlipaevi and $W$. vicina are still valid; however their cultures and published sequences may represent different species of the subfamily Leishmaniinae.

Our results argue that application of advanced microscopic techniques for species description allows much better visualization of intracellular structures and features. For example, in the case of $W$. ravinia we observed an unusual electron-dense flagellar connection with the cytosolic membrane. Furthermore, the flagellar pocket of this isolate is lacking the layer of subpellicular microtubules underneath the flagellar pocket membrane and is filled with the highly abundant helically structured electron dense material. This material is highly reminiscent of filamentous phosphoglycoprotein polymers of secreted acid phosphatase of Leishmania mexicana Biagi, 1953 Ilg et al. (1991), Stierhof et al. (1994).

Confirming previous reports (Gluenz et al. 2007), we also detected the EDTA-mediated bleaching (i.e. removal of uranyl acetate from the DNA-containing structures) of the kDNA disc, the inner unilateral filaments and lobe structures at the opposite poles of the disc. There is no kDNA disc-associated structure refractory to EDTA bleaching arguing against specific RNA processing complexes within the kDNA network. Of note, Bernhard's EDTA regressive staining of trypanosomatid nuclei results in bleaching of chromatin only, leaving RNA-containing structures such as nucleoli unbleached (data not shown). Our direct comparison of three different substitution media (see Materials and Methods) showed that all three methods were fairly efficient in staining and contrasting ultrastructural features. As demonstrated before (Seligman et al. 1966), uranyl-acetate helps increasing contrast, but OTO was found to be the most efficient method to preserve and contrast lipid-containing structures (Fig. S1).

For Crithidia otongatchiensis we observed a very prominent unpolarized Golgi apparatus and large mitochondria with extremely high number of cristae. The number of cristae, which expand the mitochondrial inner membrane surface, thus facilitating its ATP production, is known to correlate with ATP demand (Stinson et al. 1989). This implies that $C$. otongatchiensis cells may need more ATP per cell for their maintenance as compared to other 
isolates investigated here. Relatively large kinetoplast is densely packed with kinetoplast DNA. Within the disc, the minicircles are stretched out and aligned side-by-side approximately perpendicular to the planar face of the disc. Therefore, the thickness of the disc was estimated to be about a half the circumference of a minicircle (Yurchenko and Kolesnikov 2001, Lukeš et al. 2002). Judged by this criterion, minicircles of the investigated isolates are largest in C. otongatchiensis and smallest in W. ravinia cells.

Irregularly shaped flagellum-associated structure can often be seen at the flagellum pocket opening of Leptomonas moramango. Similar structures seem to be rare and so far were documented in a few species, for example, Crithidia brachyflagelli Maslov et Lukeš, 2009 and Chromera velia Moore et al., 2008 (Oborník et al. 2011, Jirků et al. 2012).

In the cases of Leptomonas moramango sp. n. and Crithidia pragensis sp. n., electron microscopy coupled with HPF allowed visualization of viral particles for the first time in a monoxenous trypanosomatid. Double stranded (ds)RNA viruses, such as LRV-1 (stands for Leishmania RNA virus-1), have been detected in several Leishmania species including L. guyanensis, and L. braziliensis before (Guilbride et al. 1992, Zamora et al. 1995, 2000, Salinas et al. 1996). Their approximately $5.3 \mathrm{~kb}$ long dsRNA genome is protected by a virus-encoded capsid. Recently, the presence of LRV-1 viruses has been correlated with metastatic potential of L. guyanensis and with severity of mucocutaneous leishmaniases (Hartley et al. 2012, Zangger et al. 2013). LRV-1 can be recognized by the host Toll-like receptor 3 and induces a potent immune response culminated in production of proinflammatory cytokines and chemokines, such as Ccl5, IL6, and TNF $\alpha$ (Ives et al. 2011). The detection of viral particles in (presumably) monoxenous trypanosomatids poses several important questions. Are these viruses related to LRV-1?
Do they facilitate infectivity of these parasites? Do they induce similar immune response in insect cells? All these questions remain to be investigated further.

Taken together, these data indicate that similarly to many cases described before (Yurchenko et al. 2008, 2009, Zídková et al. 2010, Votýpka et al. 2012b, Borghesan et al. 2013), the morphology-based approach of often highly polymorphic species has very little, if any at all, value in discrimination and/or classification of monoxenous trypanosomatids. Inclusion of ultrastructural analysis based on the HPF protocol is, however, useful as it allows occasional detection of unique or novel features, such as viruses, varying number of mitochondrial cristae or secreted acid phosphatase.

Acknowledgements. We would like to thank members of the Life Science Research Centre (University of Ostrava) and the Biology Centre (Institute of Parasitology, České Budějovice) for helpful discussions and technical assistance. The advice on taxonomy from Dr. Jan Ševčík (University of Ostrava), Dr. Alexei Kostygov (University of Ostrava and Zoological Institute, St. Petersburg) and Dr. David Modrý (Veterinary and Pharmacological University, Brno) and the help of Dr. Steven Beverley (Washington University, St. Louis) and Dr. Mark Field (University of Cambridge) with interpretation of ultrastructural features is appreciated. We are also thankful to Tomáš Bílý (Institute of Parasitology, České Budějovice) for his help with electron microscopy and data analysis. We acknowledge the use of research infrastructure that has received funding from the EU 7th Framework Programme, grant agreement No. 316304. This work was supported by Bioglobe grant CZ.1.07/2.3.00/30.0032, and Praemium Academiae award to J.L., who is also a Fellow of the Canadian Institute for Advanced Research (CIFAR), the Grant Agency of Charles University (426211) to H.K. and J.V. and the Czech Science Foundation (P506/13/24983S) to V.Y. who is also supported by the funds of the Moravskoslezský Kraj research initiative.

\section{REFERENCES}

BERNHARD W. 1969: A new staining procedure for electron microscopical cytology. J. Ultrastruct. Res. 27: 250-265.

Borghesan T.C., Ferreira R.C., Takata C.S., Campaner M., Borda C.C., Paiva F., Milder R.V., Teixeira M.M., CamarGO E.P. 2013: Molecular phylogenetic redefinition of Herpetomonas (Kinetoplastea, Trypanosomatidae), a genus of insect parasites associated with flies. Protist 164: 129-152.

BRUN R. 1974: Ultrastructure and life cycle of Herpetomonas muscarum, "Herpetomonas mirabilis" and Crithidia luciliae in Chrysomyia chloropyga. Acta Trop. 32: 219-290.

Bulat S.A., Mokrousov I.V., Podlipaev S.A. 1999: Classification of trypanosomatids from insects and plants by the UP-PCR (Universally Primed PCR) technique and cross dot blot hybridization of PCR products. Eur. J. Protistol. 35: 319-326.

Flegontov P., Votýpka J., Skalický T., Logacheva M.D., Penin A.A., Tanifuji G., Onodera N.T., Kondrashov A.S., Volf P., Archibald J.M., Lukeš J. 2013: Paratrypanosoma is a novel early-branching trypanosomatid. Curr. Biol. 23: 1787-1793.
Gerasimov E.S., Kostygov A.Y., Yan S., Kolesnikov A.A. 2012: From cryptogene to gene? ND8 editing domain reduction in insect trypanosomatids. Eur. J. Protistol. 48: 185-193.

Gluenz E., Shaw M.K., Gull K. 2007: Structural asymmetry and discrete nucleic acid subdomains in the Trypanosoma brucei kinetoplast. Mol. Microbiol. 64: 1529-1539.

Guilbride L., Myler P.J., Stuart K. 1992: Distribution and sequence divergence of LRV1 viruses among different Leishmania species. Mol. Biochem. Parasitol. 54: 101-104.

Guindon S., Delsuc F., Dufayard J.F., Gascuel O. 2009: Estimating maximum likelihood phylogenies with PhyML. Methods Mol. Biol. 537: 113-137.

Hamilton P.B., Stevens J.R., Gaunt M.W., Gidley J., Gibson W.C. 2004: Trypanosomes are monophyletic: evidence from genes for glyceraldehyde phosphate dehydrogenase and small subunit ribosomal RNA. Int. J. Parasitol. 34: 1393-1404.

Harris K.A., JR., Crothers D.M., Ullu E. 1995: In vivo structural analysis of spliced leader RNAs in Trypanosoma brucei 
and Leptomonas collosoma: a flexible structure that is independent of cap4 methylations. RNA 1: 351-362.

Hartley M.A., Ronet C., Zangger H., Beverley S.M., Fasel N. 2012: Leishmania RNA virus: when the host pays the toll. Front. Cell. Infect. Microbiol. 2: 99.

Hollar L., Lukeš J., Maslov D.A. 1998: Monophyly of endosymbiont containing trypanosomatids: phylogeny versus taxonomy. J. Eukaryot. Microbiol. 45: 293-297.

Ilg T., Stierhof Y.D., Etges R., Adrian M., Harbecke D., Overath P. 1991: Secreted acid phosphatase of Leishmania mexicana: a filamentous phosphoglycoprotein polymer. Proc. Natl. Acad. Sci. USA 88: 8774-8778.

Ives A., Ronet C., Prevel F., Ruzzante G., Fuertes-Marraco S., Schutz F., Zangger H., Revaz-Breton M., Lye L.F., Hickerson S.M., Beverley S.M., Acha-Orbea H., Launois P., Fasel N., Masina S. 2011: Leishmania RNA virus controls the severity of mucocutaneous leishmaniasis. Science 331: 775-778.

JirkŮ M., Yurchenko V.Y., Lukeš J., Maslov D.A. 2012: New species of insect trypanosomatids from Costa Rica and the proposal for a new subfamily within the Trypanosomatidae. J. Eukaryot. Microbiol. 59: 537-547.

Kostygov A.Y., Slisarenko E.P., Merkulov P.A., Podlipaev S.A. 2004: Genetic diversity of insect trypanosomatids from subarctic and North-West Russia revealed by UP-PCR typing. Protistology 3: 257-264.

Lukeš J., Guilbride D.L., Votýpka J., Zíková A., Benne R., ENGLUND P.T. 2002: Kinetoplast DNA network: evolution of an improbable structure. Euk. Cell 1: 495-502.

Malysheva M.N., Frolov A.O. 2004: [The description of Wallaceina vicina sp. n. (Kinetoplastida: Trypanosomatidae), from the water strider Gerris rufoscutellatus Latreille, 1807 (Hemiptera: Gerridae).] Parazitologiya 38: 470-476. (In Russian.)

Malysheva M.N., Frolov A.O. 2009: [On the problem of identification of homoxenous trypanosome cultures with the description of a new species Wallaceina podlipaevi sp. n. (Kinetoplastida: Trypanosomatidae).] Parazitologiya 43: 502-515. (In Russian.)

Mandelboim M., Estrano C.L., Tschudi C., Ullu E., Michaeli S. 2002: On the role of exon and intron sequences in transsplicing utilization and cap 4 modification of the trypanosomatid Leptomonas collosoma SL RNA. J. Biol. Chem. 277: 35210-35218.

Maslov D.A., Lukeš J., Jirkủ M., Simpson L. 1996: Phylogeny of trypanosomes as inferred from the small and large subunit rRNAs: implications for the evolution of parasitism in the trypanosomatid protozoa. Mol. Biochem. Parasitol. 75: 197205.

Maslov D.A., Podlipaev S.A., Lukeš J. 2001: Phylogeny of the Kinetoplastida: taxonomic problems and insights into the evolution of parasitism. Mem. Inst. Oswaldo Cruz 96: 397-402.

Maslov D.A., Votýpka J., Yurchenko V., Lukeš J. 2013: Diversity and phylogeny of insect trypanosomatids: all that is hidden shall be revealed. Trends Parasitol. 29: 43-52.

Maslov D.A., Westenberger S.J., Xu X., Campbell D.A., STURM N.R. 2007: Discovery and barcoding by analysis of spliced leader RNA gene sequences of new isolates of Trypanosomatidae from Heteroptera in Costa Rica and Ecuador. J. Eukaryot. Microbiol. 54: 57-65.

Maslov D.A., Yurchenko V.Y., Jirků M., Lukeš J. 2010: Two new species of trypanosomatid parasites isolated from Heteroptera in Costa Rica. J. Eukaryot. Microbiol. 57: 177-188.
Merzlyak E., Yurchenko V., Kolesnikov A.A., Alexandrov K., Podlipaev S.A., Maslov D.A. 2001: Diversity and phylogeny of insect trypanosomatids based on small subunit rRNA genes: polyphyly of Leptomonas and Blastocrithidia. J. Eukaryot. Microbiol. 48: 161-169.

Morio F., Reynes J., Dollet M., Pratlong F., Dedet J.P., RAVEL C. 2008: Isolation of a protozoan parasite genetically related to the insect trypanosomatid Herpetomonas samuelpessoai from a human immunodeficiency virus-positive patient. J. Clin. Microbiol. 46: 3845-3847.

Moyne G. 1980: Methods in ultrastructural cytochemistry of the cell nucleus. Prog. Histochem. Cytochem. 13: 1-72.

Oborník M., Vancová M., Lai D.H., Janouškovec J., Keeling P.J., LUKEŠ J. 2011: Morphology and ultrastructure of multiple life cycle stages of the photosynthetic relative of Apicomplexa, Chromera velia. Protist 162: 115-130.

Podlipaev S.A. 1990: [Catalogue of World Fauna of Trypanosomatidae (Protozoa).] Zoologicheskii Institut AN SSSR, Leningrad, 178 pp. (In Russian.)

Podifaev S.A. 2001: The more insect trypanosomatids under study - the more diverse Trypanosomatidae appears. Int. J. Parasitol. 31: 648-652.

Podlipaev S.A., Frolov A.O. 2000: [The phylogeny of the Trypanosomatidae: molecular and morphological approaches]. Parazitologiya 34: 169-182. (In Russian.)

Podlipaev S.A., Frolov A.O., Kolesnikov A.A. 1990: [Proteomonas inconstans $\mathrm{n}$. gen. n. sp. (Kinetoplastida, Trypanosomatidae), a parasite of the bug Calocoris sexguttatus (Hemiptera, Miridae).] Parazitologiya 24: 339-345. (In Russian.)

Podlipaev S.A., Malysheva M.N., Kolesnikov A.A. 1991: Leptomonas rigidus $\mathrm{sp}$. n. (Trypanosomatidae) - a parasite of Salda littoralis L. (Hemiptera, Heteroptera). Acta Protozool. 30: 121-127.

Podlipaev S.A., Sturm N.R., Fiala I., Fernandes O., Westenberger S.J., Dollet M., Campbell D.A., Lukeš J. 2004: Diversity of insect trypanosomatids assessed from the spliced leader RNA and 5S rRNA genes and intergenic regions. J. Eukaryot. Microbiol. 51: 283-290.

Posada D., Crandall K.A. 1998: MODElTeST: testing the model of DNA substitution. Bioinformatics 14: 817-818.

Richter K. 1994: Cutting artefacts on ultrathin cryosections of biological bulk specimens. Micron 25: 297-308.

Ronquist F., Teslenko M., van der Mark P., Ayres D.L., Darling A., Hohna S., Larget B., Liu L., Suchard M.A., Huelsenbeck J.P. 2012: MrBayes 3.2: efficient Bayesian phylogenetic inference and model choice across a large model space. Syst. Biol. 61: 539-542.

Salinas G., Zamora M., Stuart K., Saravia N. 1996: Leishmania RNA viruses in Leishmania of the Viannia subgenus. Am. J. Trop. Med. Hyg. 54: 425-429.

Seligman A.M., Wasserkrug H.L., Hanker J.S. 1966: A new staining method (OTO) for enhancing contrast of lipid-containing membranes and droplets in osmium tetroxide-fixed tissue with osmiophilic thiocarbohydrazide (TCH). J. Cell Biol. 30: 424-432.

Singh N., Chikara S., Sundar S. 2013: SOLiD sequencing of genomes of clinical isolates of Leishmania donovani from India confirm Leptomonas co-infection and raise some key questions. PLOS One 8: e55738.

Srivastava P., Prajapati V.K., Vanaerschot M., Van der Auwera G., Dujardin J.C., Sundar S. 2010: Detection of Leptomonas sp. parasites in clinical isolates of Kala-azar patients from India. Infect. Genet. Evol. 10: 1145-1150. 
Stierhof Y.D., Ilg T., Russell D.G., Hohenberg H., Overath P. 1994: Characterization of polymer release from the flagellar pocket of Leishmania mexicana promastigotes. J. Cell Biol. 125: 321-331.

Stinson S., Sommer J.R., Blum J.J. 1989: Morphology of Leishmania braziliensis: changes during reversible heat-induced transformation from promastigote to an ellipsoidal form. J. Parasitol. 75: 431-440.

Svobodová M., Zidková L., ČepičKa I., OboRník M., LukeŠ J., VotÝPKa J. 2007: Sergeia podlipaevi gen. nov., sp. nov. (Trypanosomatidae, Kinetoplastida), a parasite of biting midges (Ceratopogonidae, Diptera). Int. J. Syst. Evol. Microbiol. 57: $423-432$.

Swofford D.L. 2001: PAUP*. Phylogenetic Analysis Using Parsimony (*and Other Methods). Version 4., Sinauer Associates, Sunderland, MA, USA.

Teixeira M.M., Borghesan T.C., Ferreira R.C., Santos M.A., Takata C.S., Campaner M., Nunes V.L., Milder R.V., De Souza W., Camargo E.P. 2011: Phylogenetic validation of the genera Angomonas and Strigomonas of trypanosomatids harboring bacterial endosymbionts with the description of new species of trypanosomatids and of proteobacterial symbionts. Protist 162: 503-524.

Teixeira M.M., Takata C.S., Conchon I., Campaner M., CaMARGO E.P. 1997: Ribosomal and kDNA markers distinguish two subgroups of Herpetomonas among old species and new trypanosomatids isolated from flies. J. Parasitol. 83: 58-65.

Thompson J.D., Gibson T.J., Higgins D.G. 2002: Multiple sequence alignment using ClustalW and ClustalX. Curr. Protoc. Bioinformatics Chapter 2: Unit 23.

TÝČ J., Votýpka J., Klepetková H., Šulaková H., JiRkŮ M., LUKEŠ J. 2013: Growing diversity of trypanosomatid parasites of flies (Diptera: Brachcera): frequent cosmopolitism and moderate host specificity. Mol. Phylogenet. Evol. 69: 255-264.

Votýpka J., Klepetrová H., Jirkủ M., Kment P., Lukeš J. 2012a: Phylogenetic relationships of trypanosomatids parasitising true bugs (Insecta: Heteroptera) in sub-Saharan Africa. Int. J. Parasitol. 42: 489-500.

Votýpka J., Klepetková H., Yurchenko V.Y., Horák A., Lukeš J., Maslov D.A. 2012b: Cosmopolitan distribution of a trypanosomatid Leptomonas pyrrhocoris. Protist 163: 616-631.

Votýpka J., Maslov D.A., Yurchenko V., JirkŮ M., Kment P., Lun Z.R., Lukeš J. 2010: Probing into the diversity of trypanosomatid flagellates parasitizing insect hosts in SouthWest China reveals both endemism and global dispersal. Mol. Phylogenet. Evol. 54: 243-253.

Votýpka J., Suková E., Kraeva N., Ishemgulova A., Duží I., Lukeš J., Yurchenko V. 2013: Diversity of trypanosomatids (Kinetoplastea: Trypanosomatidae) parasitizing fleas (Insecta: Siphonaptera) and description of a new genus Blechomonas gen. n. Protist 164: 763-781.
WALLACE F.G. 1966: The trypanosomatid parasites of insects and arachnids. Exp. Parasitol. 18: 124-193.

Wallace F.G., Clark T.B., Dyer M.I., Collins T. 1960: Two new species of flagellates cultivated from insects of the genus Gerris. J. Protozool. 7: 390-392.

Westenberger S.J., Sturm N.R., Yanega D., Podlipaev S.A., Zeledon R., Campbell D.A., Maslov D.A. 2004: Trypanosomatid biodiversity in Costa Rica: genotyping of parasites from Heteroptera using the spliced leader RNA gene. Parasitology 129: $537-547$.

Willingham M.C., Rutherford A.V. 1984: The use of osmiumthiocarbohydrazide-osmium (OTO) and ferrocyanide-reduced osmium methods to enhance membrane contrast and preservation in cultured cells. J. Histochem. Cytochem. 32: 455-460.

Yurchenko V.Y., Kolesnikov A.A. 2001: Minicircular kinetoplast DNA of Trypanosomatidae. Mol. Biol., Moscow 35: 3-13.

Yurchenko V.Y., Lukeš J., Jirkủ M., Maslov D.A. 2009: Selective recovery of the cultivation-prone components from mixed trypanosomatid infections: a case of several novel species isolated from Neotropical Heteroptera. Int. J. Syst. Evol. Microbiol. 59: 893-909.

Yurchenko V.Y., Lukeš J., Jirků M., Zeledón R., Maslov D.A. 2006a: Leptomonas costaricensis sp. n. (Kinetoplastea: Trypanosomatidae), a member of the novel phylogenetic group of insect trypanosomatids closely related to the genus Leishmania. Parasitology 133: 537-546.

Yurchenko V.Y., Lukeš J., Tesařová M., Jirkư M., Maslov D.A. 2008: Morphological discordance of the new trypanosomatid species phylogenetically associated with the genus Crithidia. Protist 159: 99-114.

Yurchenko V.Y., Lukeš J., Xu X., Maslov D.A. 2006b: An integrated morphological and molecular approach to a new species description in the Trypanosomatidae: the case of Leptomonas podlipaevi n. sp., a parasite of Boisea rubrolineata (Hemiptera: Rhopalidae). J. Eukaryot. Microbiol. 53: 103-111.

Zamora M., Guilbride L., Sacks L., Stuart K. 2000: Phylogenetic analysis of the 5' subterminal region of isolates of Leishmania RNA virus-1. Ann. Trop. Med. Parasitol. 94: 123-133.

ZAMORA M., SACKs L., StUART K. 1995: Intracellular localization of LRV1 in infected Leishmania cells and epitope conservation of the coat protein. J. Eukaryot. Microbiol. 42: 580-582.

Zangger H., Ronet C., Desponds C., Kuhlmann F.M., Robinson J., Hartley M.A., Prevel F., Castiglioni P., Pratlong F., Bastien P., Muller N., Parmentier L., Saravia N.G., Beverley S.M., Fasel N. 2013: Detection of Leishmania RNA virus in Leishmania parasites. PLoS Negl. Trop. Dis. 7: e2006.

Zídková L., ČepičKa I., VotÝPKa J., Svobodová M. 2010: Herpetomonas trimorpha sp. nov. (Trypanosomatidae, Kinetoplastida), a parasite of the biting midge Culicoides truncorum (Ceratopogonidae, Diptera). Int. J. Syst. Evol. Microbiol. 60: 2236-2246.

Accepted 4 December 2013 